\title{
Lipofuscin as an indicator of age in crustaceans: analysis of the pigment in the American lobster Homarus americanus
}

\author{
Richard A. Wahle ${ }^{1, *}$, Oliver Tully ${ }^{2}$, Vera O'Donovan ${ }^{2}$ \\ ${ }^{1}$ Bigelow Laboratory for Ocean Sciences, West Boothbay Harbor, Maine 04575, USA \\ ${ }^{2}$ Department of Zoology, Trinity College, Dublin 2, Ireland
}

\begin{abstract}
Lipofuscin content was determined in the brains of 41 American lobsters Homarus americanus (Milne-Edwards) aged 4,13 and 27 mo reared individually at 19 to $20^{\circ} \mathrm{C}$. Lipofuscin was quantified by fluorescence microscopy and image analysis. Lipofuscin granules occurred in each age group and in the oldest group appeared as large aggregations collectively averaging $2.1 \%$ of the area of histological sections of the olfactory lobe cell mass. Carapace length-corrected lipofuscin area \% gave the highest correlation with age $(r=0.99, p<0.0001)$ and a non-linear best fit regression $(y=0.00264 \times$ Age ${ }^{2.03}$ ). The size and number of lipofuscin granules and carapace length were also significantly related to age. Lipofuscin concentration was not significantly correlated with carapace length within any of the 3 age classes ( $4 \mathrm{mo}: \mathrm{r}=-0.078,13 \mathrm{mo}: \mathrm{r}=-0.20 .27 \mathrm{mo}: \mathrm{r}=-0.351$ ). These results suggest the possibility that the lipofuscin technique can differentiate cohorts in natural populations. However, environmental temperature and the possibility of other factors affecting metabolic rate may need to be taken into account when attempting to apply the laboratory model to wild populations.
\end{abstract}

KEY WORDS: Age determination - Age pigment Physiological age - Image analysis - Fluorescence - Demography

\section{INTRODUCTION}

The determination of age in crustaceans has been a long-standing technical problem for investigators because neither body size nor other morphological structures provide a reliable index of age. Traditionally, cohort analysis of crustacean populations has depended on size-frequency distributions to which normal curves are fitted to extract age classes (MacDonald \& Pitcher 1979, Tully \& Hillis 1995). Although body size may give a rough estimate of age, on its own it is a rather poor indicator because of the dependence of growth on a variety of environmental conditions such as temperature, nutritional status, and crowding, to mention a few ( $\mathrm{Ra}^{\prime}$ anan \& Cohen 1985). An accurate and dependable aging technique would greatly

\footnotetext{
·E-mail: rwahle@bigelow.org
}

enhance the analysis of cohorts in crustacean populations and facilitate the management of exploited populations.

There has been cautious optimism that the fluorescent age pigment, lipofuscin, may be an accurate indicator of age. Eldred \& Lasky (1993) recently identified the structure of the fluorophore as resulting from a Schiff base reaction product of retinaldehyde and ethanolamine in human retinal pigment epithelium. The pigment may also arise as a product of lipid peroxidation caused by free radical activity and its rate of formation may, therefore, depend mainly on the rate of cellular oxygen consumption (Brizzee \& Ordy 1981. Donato 1981, Katz et al. 1984). The amount of pigment, therefore, may be related to physiological age more than to chronological age, but may still be a more valuable indicator of chronological age than body size if proper quantification procedures are applied (e.g. Nicol 1987, Sheehy 1989, Sheehy 1990b). For some 
time, chemically extracted fluorescent pigments have been used as indicators of age in insects (Ettershank 1983, Mail et al. 1983). These methods when applied to crustaceans have given ambiguous results in many cases (Hirche \& Anger 1987, Berman et al. 1989) and have certain fundamental limitations (Nicol 1987, Sheehy \& Roberts 1991, Sheehy in press). More recently, histologically based quantification of yellow fluorescing morphological lipofuscin in Cherax spp. (Sheehy 1989, 1990a, b, 1992, Sheehy et al. 1994), Nephrops norvegicus (Belchier et al. 1994), Penaeus monodon (Sheehy et al. 1995a), and Homarus gammarus (O'Donovan \& Tully in press) has yielded more positive indications of an age-specific accumulation in crustaceans. This work is, however, still in a developmental phase. Some of the most important issues relate to the variation in lipofuscin quantities between and within known-age year groups and to the relationship between body size and lipofuscin within age groups.

The objective of this study was to determine: (1) the age-dependence of lipofuscin in Homarus americanus, a species for which no published data currently exists; and (2) the relationship between lipofuscin and body size within age classes. We reasoned that if lipofuscin concentrations increased significantly with age, but were independent of body size within an age group, there could be great potential for the technique in differentiating cohorts because, in that case, lipofuscin would be independent of the processes leading to high variability in size at age.

\section{METHODS}

Three age groups of hatchery-reared Homarus americanus (Milne-Edwards) were obtained from Kona Kold Lobsters Ltd., Hawaii, USA. These were $4(\mathrm{n}=10), 13$ ( $\mathrm{n}$ $=21)$, and $27(n=10)$ mo old and were grown in individual containers at 19 to $20^{\circ} \mathrm{C}$. Container size was $46 \mathrm{~cm}^{2}$ for the 4 and 13 mo old lobsters. The third age group was held in $46 \mathrm{~cm}^{2}$ containers for 9 mo and subsequently in $131 \mathrm{~cm}^{2}$ for $6 \mathrm{mo}$, then in $252 \mathrm{~cm}^{2}$ containers for $12 \mathrm{mo}$. Lobsters were fed frozen San Francisco Bay brand Artemia before weaning onto pelletized food.

Lobster heads were fixed in 10\% formal saline and shipped to Trinity College, Dublin, Ireland. There the brains were dissected and embedded in paraffin after dehydration in alcohols and clearing in xylene. Sections $(6 \mu \mathrm{m})$ of the olfactory lobe cell mass were mounted in DPX. To be consistent with previous studies, sections were analyzed from the basal region of the olfactory lobe cell mass (see Sheehy 1990a). In this study, lipofuscin in the olfactory lobe cell mass was detected under a $20 \times$ microscope objective using epifluorescence with a halogen light source and B2-A
(450 to $490 \mathrm{~nm}$ ) excitation filter (Sheehy 1989). The amount of lipofuscin present in the sections was quantified by image analysis. A cooled CCD (chargecoupled device) integrating camera sampled the image from the microscope at defined intervals and integrated a set number of samplings thereby enhancing the clarity of the resulting image. The image was displayed on a $37.5 \mathrm{~cm}$ RGB (red green blue) high resolution image monitor and processed using a video card set with 8 bit $512 \times 512$ pixel resolution and pseudocolor RGB outputs. The system supported GENIAS and RESULTS (Applied Imaging, UK) image andysis software for processing routines and full statistical analysis respectively. The total field area of the captured images was $4.95 \times 10^{4} \mu \mathrm{m}^{2}$. Up to five $6.0 \mu \mathrm{m}$ sections of the appropriate area of the olfactory cell mass were analyzed for each lobster For each section we quantified: (1) the area \%, the percent of the cell mass occupied by ilpofuscin; (2) the density of lipofuscin granules per $100 \mu \mathrm{m}^{2}$ of cell mass; and (3) the mean diameter of lipofuscin granules. The coefficient of variation (CV) was calculated as a percent for each set of 5 replicates of area \%.

Statistical analysis. Lipofuscin was quantified in 5 tissue sections for each lobster, and a number of lobsters were thus analyzed within each of 3 cohorts. Our principal interest was to relate lipofuscin content to age. Because of the structure of the data, however, it was also possible to compare the variation in lipofuscin concentration between cohorts to that within cohorts and within individual lobsters. The data on lipofuscin area $\%$, granule density, and mean size were analyzed separately by a mixed model 2-level nested ANOVA; variance components were estimated for samples with unequal sizes (Sokal \& Rohlf 1981). Data were transformed by the natural logarithm before analysis to homogenize variances. The relative magnitudes of the variance components, expressed as percentages, indicated the contribution to total sums of squares from each level in the nested data. The contribution to variation from each source raises important issues for the lipofuscin technique described here. For example, high within-lobster variation would indicate the need to analyze a greater number of tissue sections per individual, while high within-age relative to among-age variance would indicate substantial individual variation between lobsters independent of age.

The relationship between age and carapace length and age and lipofuscin area \% was modeled by leastsquares regression. We did not model lipofuscin granule density or size because the area \% separated age groups most efficiently in the ANOVA and the other 2 variables are highly correlated with area \%. Linear and power functions were fitted to the pigmentage relationship based on a best least-squares fit to the 
data. In addition, regression modeling was carried out using carapace length as a covariate in the analysis. This removed any influence of body size from the lipofuscin-age regression (Sokal \& Rohlf 1981). Pearson correlation coefficients (r) were also generated to test for relationships between carapace length and lipofuscin content within each age group.

\section{RESULTS}

Lipofuscin was readily visible in the olfactory lobes of all 3 age groups of Homarus americanus (Fig 1). The average $\mathrm{CV} \pm 1 \mathrm{SD}$ was $36.2 \% \pm 17.0$ for the 41 specimens in the study. Older lobsters had greater amounts of lipofuscin than younger ones (Fig. 1, Tables 1 $\& 2)$. While carapace length of the oldest and youngest age groups differed by a factor of about 4, the lipofuscin concentrations differed by a factor of almost 50 . The 4 mo old lobsters typically had few and small-sized granules of pigment while the 27 mo old lobsters had many more and larger aggregations, the largest at $872 \mu^{2}$. Lipofuscin granule size increased significantly from 4 to 13 to 27 mo (Tables 1 \& 2; Scheffe's post-hoc test, p < $0.0001)$. The greatest increase accurred between 13 and 27 mo (Table 1). The density of granules increased significantly from 4 to 13 mo $(\mathrm{p}<0.0001)$, but not between 13 and $27 \mathrm{mo}(\mathrm{p}>0.2)$.

A total of $83 \%$ of the variation in lipofuscin area \% was explained by age (Table 2). An additional, and statistically significant, $12.8 \%$ of the total variance was among individual lobsters within ages. Error variance, due to differences among tissue sections within each lobster, contributed $4.4 \%$ to the total variation. Partitioning of variance in lipofuscin granule density and granule size gave similar results.

Carapace length increased linearly with age (Fig. 2A; $\mathrm{r}^{2}=0.92$ ). Lipofuscin area \% alone increased as a power function of age (Fig. 2B; $\left.r^{2}=0.83\right)$. The fit of this relationship was improved further after removing any effect of body size by analysis of covariance (Fig. 2C; $\mathrm{r}^{2}$ $=0.98$ ).

Within age groups lipofuscin area \% was was not significantly dependent on body size over the range of body sizes sampled (Fig. 3). For the range of body sizes sampled in each age group, none of the correlation coefficients was significantly different from zero.
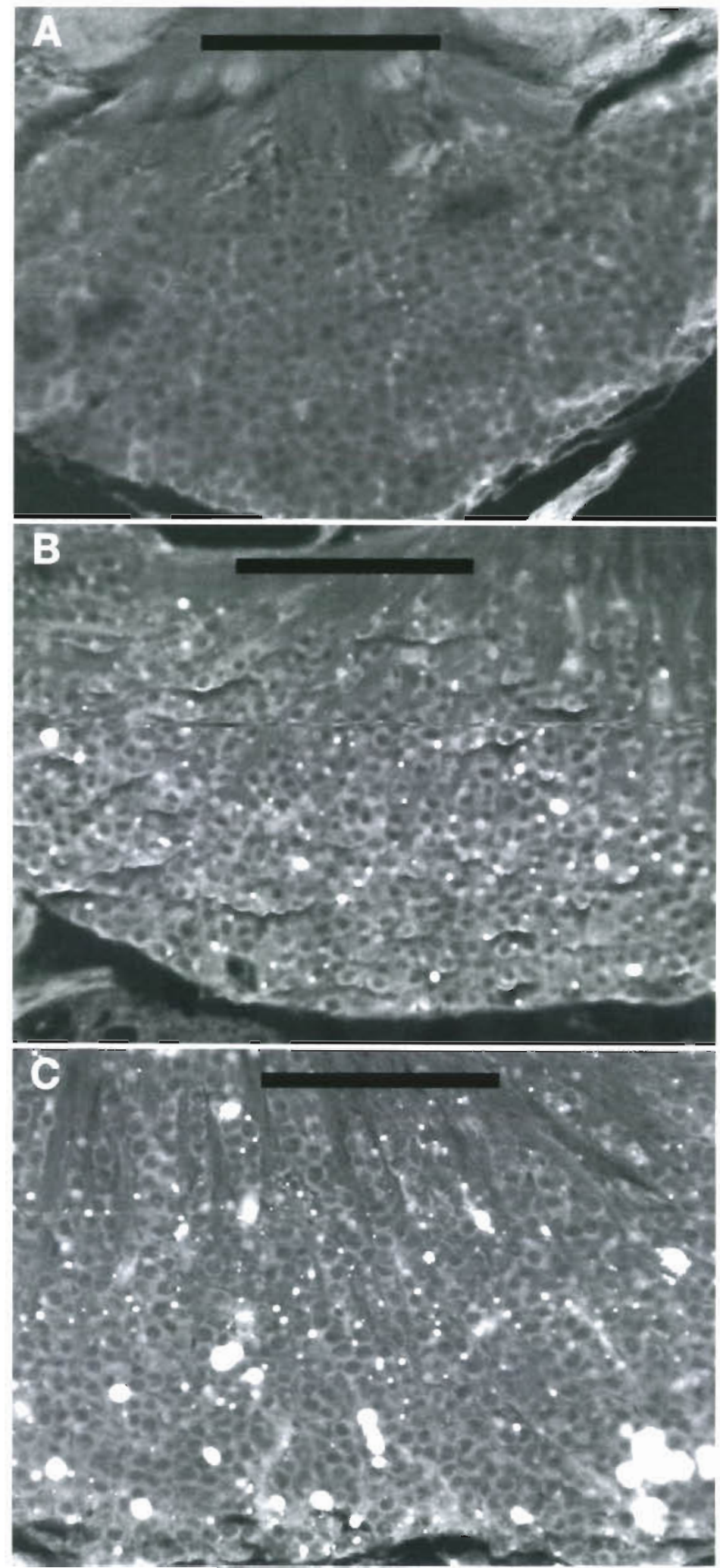

Fig. 1. Homarus americanus. Photographs of sections of the olfactory cell mass of lobsters at ages (A) 4, (B) 13, (C) 27 mo with fluorescing lipofuscin granules. Lobsters reared at 19 to $20^{\circ} \mathrm{C}$. Halogen light source with B2-A (450 to $490 \mathrm{~nm}$ ) excitation filter. Scale bar $=300 \mu \mathrm{m}$ 
Table 1. Mean size and rnefficient of variation (as a $\%$ in parentheses) of lobster size and lipofuscin area \%, granule size, and density for each of 3 age groups of Homarus americanus. F-ratios of raw and $\log$-transformed data are all significant at $p<0.0001$. (See Fig. 2 for regression analysis)

\begin{tabular}{|c|c|c|c|}
\hline & $\begin{array}{c}4 \\
n=10\end{array}$ & $\begin{array}{c}\text { Age }(\mathrm{mo}) \\
13 \\
\mathrm{n}=21\end{array}$ & $\begin{array}{c}27 \\
n=10\end{array}$ \\
\hline Carapace length (mm) & $8.95 \quad(10)$ & $17.3(18)$ & $33.6 \quad(6)$ \\
\hline \multicolumn{4}{|l|}{ Lipofuscin } \\
\hline Area percent & $0.05 \quad(55)$ & $0.54(49)$ & $2.10(30)$ \\
\hline Granule size $(\mu \mathrm{m})$ & $1.23(10)$ & $1.91(24)$ & $7.63(31)$ \\
\hline Granule density ( $\mu^{\prime-2}$ ) & $0.038(52)$ & $0.25(54)$ & $0.37(60)$ \\
\hline
\end{tabular}

\section{DISCUSSION}

Lipofuscin was detected in 4, 13 and 27 mo old Homarus americanus cultured individually at 19 to $20^{\circ} \mathrm{C}$. A noticeable feature of the lipofuscin in the brains of the 27 mo old lobsters was the very large aggregations of pigment in the olfactory lobe cell mass, some larger than the diameter of the neighboring cells (Fig. 1C). We also noticed little increase in lipofuscin granule density after the first year although granule size continued to grow. This suggests that all potential deposition sites became occupied during the first year but that granules at these sites continued to accrete pigment into the second year. The levels of lipofuscin in the 27 mo old lobsters were almost identical to those reported by Sheehy (1992) for 30 mo old Cherax quadricarinatus, which in this short-lived species were relatively 'old' individuals. These levels were also only slightly lower than those recorded by Tully (unpubl.) in wild Homarus gammarus ranging in size from 100 to $120 \mathrm{~mm}$ carapace length and at a probable age of greater than 6 yr. These observations support the hypothesis that lipofuscin concentrations reflect physiological age, the accumulated metabolism of individuals, rather than simply the passage of time, and agrees with the lipofuscin-temperature correlations found for Cherax cuspidatus (Sheehy 1990a) and H. gammarus (O'Donovan \& Tully in press).

The concentrations of lipofuscin in Homarus americanus indicated a quite high rate of physiological aging in the population sampled here. The quantity of lipofuscin was significantly related to age, and this relationship was best described by a positive power function, rather than a linear function, suggesting an increase in the rate of accumulation of lipofuscin with age. We have no immediate explanation for this apparent acceleration in lipofuscin accumulation with age, but it suggests that an increase in metabolic rate occurred. Temperature, which is expected to have the major effect on metabolic rate, remained constant in culture although the space allocation to individuals was increased in the second year on 2 occasions. The increased space may have augmented activity and or food intake which could have increased metabolic rate.

A linear lipofuscin-to-age relationship was observed in Homarus gammarus spanning the same age range as in this study, but where culture temperature averaged $13.5^{\circ} \mathrm{C}$ (O'Donovan \& Tully in press). A similar linear increase was observed by Sheehy (1990b) in Cherax quadricarinatus up to 12 mo old, but was later amended to a curvilinear negative exponential model (Sheehy 1992) or sigmoidal model (Sheehy et al. 1994) when older animals and other temperature regimes were included. Our accumulation curve is similar to the very first part of the accumulation curve for $C$. quadricarinatus in which there is a period of geometric increase in lipofuscin concentration at the start of development (Sheehy 1990a). In the crayfish this is the first 20th of the life span (M. R. J. Sheehy pers. comm.). In $H$. americanus the first 20 th of the life span may be closer to $2 \mathrm{yr}$. A declining rate of lipofuscin accumulation with age, however, would agree with the expected whole-organism reduction in weight-specific metabolic rate which occurs with greater size and age (Lockwood 1968). It would perhaps be more relevant, however, to know the age-brain metabolic rate relationship, if lipofuscin is produced within the olfactory lobe cell mass. Linear models may fit narrow ranges of ages, although there is evidence for a declining rate as a wide range of age classes is included. A positive

Table 2. Mixed model 2-level nested analysis of variance for lipofuscin area $\%$, granule density (n per $100 \mu \mathrm{m}^{2}$ ), and granule size $\left(\mu \mathrm{m}^{2}\right.$ ) among 3 cohorts of Homarus amencanus. Variance components for each source of variation are indicated

\begin{tabular}{|lccccccc|}
\hline Source of variance & df & SS & MS & $F$ & $p$ & $\begin{array}{c}\text { Variance } \\
\text { component (\%) }\end{array}$ \\
\cline { 1 - 5 } & & & & & & & \\
Lipofuscin area \% & & & & & & \\
Age & 2 & 396 & 198.2 & 79.5 & $<0.0001$ & 82.7 \\
Lobsters within age & 38 & 94 & 2.5 & 14.2 & $<0.0001$ & 12.8 \\
Within lobster & 153 & 27 & 0.2 & & & 4.4 \\
Lipofuscin granule density & & & & & \\
Age & 2 & 166 & 83.4 & 40.3 & $<0.0001$ & 69.3 \\
Lobsters within age & 38 & 78.6 & 2.1 & 11.0 & $<0.0001$ & 20.7 \\
Within lobster & 153 & 28.8 & 0.2 & & & 9.9 \\
Lipofuscin granule size & 2 & 86.9 & 43.5 & 136.0 & $<0.0001$ & 82.9 \\
Age & 38 & 12.1 & 0.3 & 3.2 & $<0.0001$ & 5.2 \\
Lobsters within age & 153 & 15.3 & 0.1 & & & 11.7 \\
Within lobster & & & & & & \\
\hline
\end{tabular}


power function, in contrast, provided the best fit to the data range presented here

Because lobsters in this study were reared at constant elevated temperatures, they grew faster and aged physiologically at a faster rate than might be expected in the same period of time in most of this species' natural range. Therefore, there is greater separation in size among the 3 cohorts than might be expected in a natural population. Body size in this study was also more closely correlated to age than might be expected in a natural or communally reared population. This was probably an artifact of the individual housing conditions at the culture system where these lobsters were reared. Living space and social interactions are known to influence growth in crayfish and lobsters. Growth of individually housed lobster are
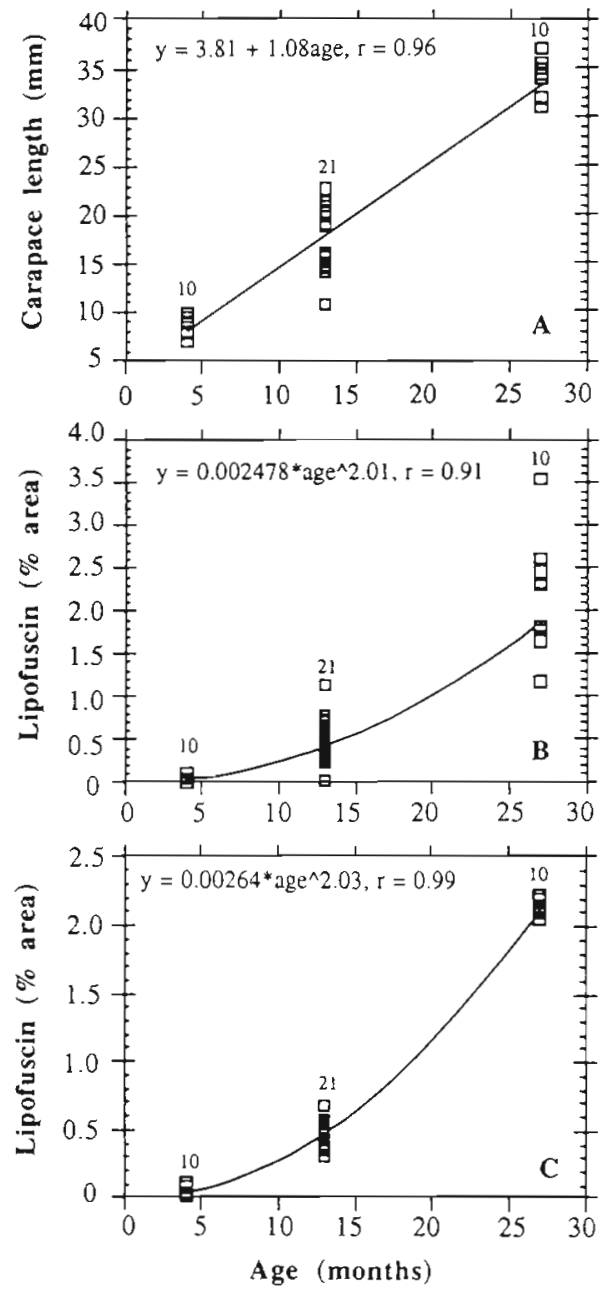

Fig. 2. Homarus americanus. Relationship between age and (A) carapace length, (B) lipofuscin area \%, and (C) lipofuscin area \% using carapace length as a covariate. The regression models were chosen on the basis of the best least-squares fit. The number of lobsters in each age category is indicated. See Tables $1 \& 2$ for descriptive statistics and $F$-ratios
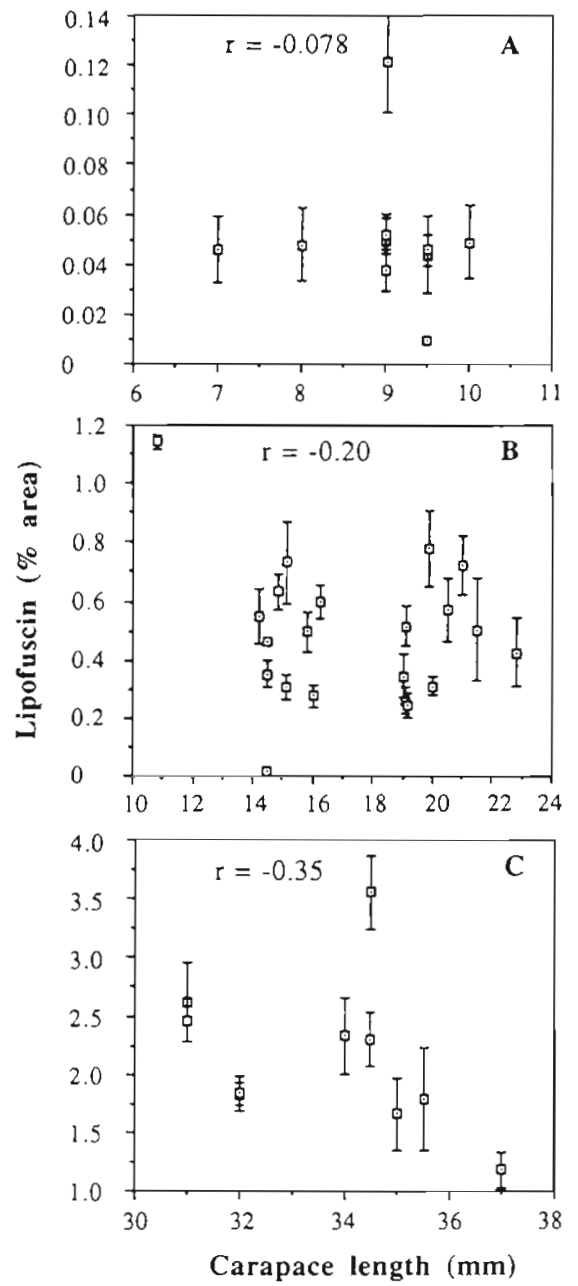

Fig. 3. Homarus americanus. Relationship between carapace length and lipofuscin area \% in lobsters aged (A) 4, (B) 13, and (C) $27 \mathrm{mo}$. Each data point and error bar represents the mean $\pm 1 \mathrm{SE}$ of 5 histological sections per brain. Pearson's correlation coefficients $(\mathrm{r})$ are indicated; none are significantly different from zero $(p>0.05)$

known to be inhibited by limited living space (van Olst et al. 1976, author's pers. obs.). Agonistic interactions also inhibit growth in subordinate lobsters (Tamm \& Cobb 1978). These social effects may even occur without physical contact. Nelson et al. (1980) found that lobsters grew more slowly when housed individually downstream from other lobsters in a laboratory raceway, possibly indicating a chemically mediated response. The mechanism by which growth is suppressed, however, is unclear.

The independence of lipofuscin and body size indicated in this study suggests that slower growth may not necessarily be due to a suppression of metabolic rate as would be expected if activity and food intake was inhibited by the presence of other individuals. 
Alternatively, energy may be reallocated from growth to other physiological or behavioral functions while maintaining overall metabolic rate. Significantly different lipofuscin levels in lobsters of the same age point to differences in metabolic rate or in the accumulated metabolism of individuals of the same age and reared under the same conditions. Whatever the cause of this individuality in lipofuscin content, it does not seem to be coupled with factors controlling body size. O'Donovan \& Tully (in press) also showed that body size and lipofuscin levels were uncorrelated in individually reared Homarus gammarus. Sheehy (1990a), in contrast, found a significant body size-to-lipofuscin relationship in $44 \mathrm{wk}$ old crayfish Cherax cuspidatus spanning a larger within-age size range than the lobsters in this study. However, further studies on a wider range of ages, sizes, and temperature regimes (Sheehy et al. 1994, 1995b) have failed to confirm this relationship. An important topic for future research would be to identify the factors leading to different levels of lipofuscin in lobsters of the same age, and to assess how important these might be in natural populations.

Significant differences in lipofuscin levels in lobsters of the same age could limit the application of the lipofuscin aging studies. In this study, however, the range in lipofuscin within age classes was quite low relative to the differences between age classes. At lower, more natural temperatures the differences between age groups in both body size and lipofuscin are likely to be smaller (Sheehy et al. 1994, 1995b). Over the range of the American lobster, temperatures vary dramatically geographically and seasonally. For example, in coastal southern New England sea surface temperatures typically vary between 3 and $22^{\circ} \mathrm{C}$, in the northern Gulf of Maine between 3 and $12^{\circ} \mathrm{C}$ (Colton \& Stoddard 1972).

In this study we found a highly significant relationship between lipofuscin and age in 3 cohorts of juvenile Homarus americanus reared at elevated temperatures. Further research should monitor the accumulation of age pigments in older cohorts and under different thermal regimes to determine the utility of the technique as an indicator of age in natural populations throughout the species' range. Alternatively, the frequency distribution of the pigment in wild populations may indicate chronological age classes more reliably than length frequency distributions (Ettershank 1983, Sheehy \& Wickins 1994, Sheehy et al. 1994). Recently, it has become possible to accurately census benthic $H$. americanus from the time of settlement (Incze \& Wahle 1991, Wahle \& Steneck 1991). From the resulting size distributions of lobsters and known growth rates of the $0+$ cohort (Wahle unpubl.) it is possible to distinguish the first year class with certainty using size alone. This would enable validation of the lipofuscin technique, at least as applied to natural populations for this year class. Environmental effects notwithstanding, this study indicates a strong correlation between lipofuscin and age and suggests that the pigment may successfully resolve juvenile age groups in natural populations of $H$. americanus.

Acknowledgements. This research was supported by grants from the National Science Foundation (\#OCE-9205931) and the Sea Grant Programs of Connecticut, Maine, and Rhode Island to R.A.W., and from the Commission of the European Communities Fisheries \& Aquaculture Research Program (FAR project \#MA 3651 ) to O.T. and V.O. We appreciate the support of Sea Grant's Ir-Am Aqua Technology Exchange program in facilitating this project. We thank D. Goodale of Kona Kold Lobsters, Ltd. for donating the lobsters for this study. Helpful assistance in processing the samples was provided by J. Burke and S. Sampson. The manuscript benefited from critical readings by M. R. J. Sheehy and 3 anonymous reviewers

\section{LITERATURE CITED}

Belchier M, Shelton PMJ, Chapman CJ (1994) The identification and measurement of fluorescent age-pigment abundance in the brain of a crustacean (Nephrops norvegicus) by confocal microscopy. Comp Bioch Physiol 108B (2): $157-164$

Berman MS, McVey AL, Ettershank G (1989) Age determination of Antarctic krill using fluorescence and image analysis of size. Polar Biol 9:267-271

Brizzee KR, Ordy JM (1981) Cellular features, regional accumulation and prospects of modification of age pigments in mammals. In: Sohal RS (ed) Age pigments. Elsevier/Nortb Holland Biomedical Press, Amsterdam, p 102-145

Colton JB, Stoddard RR (1972) Average monthly seawater temperatures: Nova Scotia to Long Island, 1940-1959. Serial atlas of the marine environment, Folio 21. Am Geogr Soc, New York

Donato $\mathrm{H} J \mathbf{r}$ (1981) Lipid peroxidation, cross linking reactions and ageing. In: Sohal RS (ed) Age pigments. Elsevier/ North Holland Biomedical Press, Amsterdam, p 63-96

Eldred GE, Lasky MR (1993) Retinal age pigments generated by self-assembling lysosomotropic detergents. Nature $361: 724-726$

Ettershank G (1983) Age structure and cyclical annual size change in the Antarctic krill, Euphausja superba. Polar Biol 2:189-193

Hirche HJ, Anger K (1987) The accumulation of age pigments during the larval development of the spider crab, Hyas araneus (Decapoda, Majıdae). Comp Biochem Physiol 88B(3):777-782

Incze LS, Wahle RA (1991) Recruitment from pelagic to early benthic phase in lobsters Homarus americanus. Mar Ecol Prog Ser 79:77-87

Katz M, Robison WG Jr, Herrmann RK, Groome AB, Bieri JG (1984) Lipofuscin accumulation resulting from senescence and vitamin $E$ deficiency: spectral properties and tissue distribution. Mech Ageing Dev 25:149-159

Lockwood APM (1968) Aspects of the physiology of the crustacea. Oliver \& Boyd, London

MacDonald PDM, Pitcher TJ (1979) Age groups from size frequency data: a versatile and efficient method of 
analyzing distribution mixtures. J Fish Res Bd Can 36: 987-1001

Mail TS, Chadwick J, Lehane MJ (1983) Determining the age of adults of Stomoxys calcitrans (L.) (Dipetra: Muscidae). Bull Entomol Res 73:501-525

Nelson K, Hedgecock D, Borgeson W, Johnson E, Daggett R, Aronstein D (1980) Density-dependent growth inhibition in lobsters, Homarus americanus (Decapoda, Nephropidae). Biol Bull 159:162-176

Nicol S (1987) Some limitations on the use of the lipofuscin ageing technique. Mar Biol 93:609-614

O'Donovan $V$, Tully $O$ (in press) Lipofuscin (age pigment) as an index of age in crustaceans: correlation with age and temperature in cultured juvenile Homarus gammarus (L.). J Exp Mar Biol Ecol

Ra'anan Z, Cohen D (1985) Ontogeny of social structure and population dynamics in the giant freshwater prawn, Macrobrachium rosenbergii (de Man). In: Wenner AM (ed) Crustacean issues 3. Factors in adult growth. AA Balkema, Rotterdam, p 277-311

Sheehy MRJ (1989) Crustacean brain lipofuscin: an examination of the morphological pigment in the freshwater crayfish, Cherax cuspidatus. J Crust Biol 9:387-391

Sheehy MRJ (1990a) Individual variation in and the effect of rearing temperature and body size on the concentration of fluorescent morphological lipofuscin in the brains of freshwater crayfish, Cherax cuspidatus (Crustacea: Parastacidae). Comp Biochem Physiol 96A:281-286

Sheehy MRJ (1990b) Potential of morphological lipofuscin age pigment as an index of crustacean age. Mar Biol $107: 439-442$

Sheehy MRJ (1992) Lupofuscin age pigment accumulation in the brains of aging field and laboratory reared crayfish Cherax quadricarinatus (von Martens) (Decapoda: Parastacidae). J Exp Mar Biol Ecol 161:79-89

This article was presented by K. Sherman (Senior Editorial Advisor), Narragansett, Rhode Island, USA
Sheehy MRJ (in press) Quanititative comparison of in situ lipofuscin concentration with soluble autofluorescence intensity in the crustacean brain. Exp Gerontol

Sheehy MRJ, Cameron E, Marsden G, McGrath J (1995a) Age structure of female giant tiger prawns Penaeus monodon as indicated by neuronal lipofuscin concentration. Mar Ecol Prog Ser 117:59-63

Sheehy MRJ, Greenwood JG, Fielder DR (1994) More accurate chronological age determination of crustaceans from field situations using the physiological age marker, lipofuscin. Mar Biol 122:237-245

Sheehy MRJ, Greenwood JG, Fielder DR (1995b) Lipofuscin as a record of rate of living in an aquatic poikilotherm. J Gerontol 50A (6):B327-336

Sheehy MRJ, Roberts BE (1991) An alternative explanation for anomolies in 'soluble lipofuscin' fluorescence data from insects, crustaceans, and other aquatic species. Exp Gerontol 26:495-509

Sheehy MRJ, Wickins JF (1994) Lipofuscin age pigment in the brain of the European lobster Homarus gammarus (L.). Microscopy Analy 12:23-25

Sokal RR, Rohlf FJ (1981) Biometry. Freeman \& Co., New York

Tamm GR, Cobb JS (1978) Behavior and the crustacean molt cycle: changes in aggression of Homarus americanus. Science 200:79-81

Tully O, Hillis JP (1995) Causes and spatial scales of variability in population structure of Nephrops norvegicus (L.) in the Irish Sea. Fish Res 21:329-347

Van Olst JC, Carlberg JM, Ford RF (1976) Effects of substrate type and other factors on the growth, survival, and cannibalism of juvenile Homarus americanus in mass rearing systems. Proc World Mariculture Soc 6:261-274

Wahle RA, Steneck RS (1991) Recruitment habitats and nursery grounds of the American lobster Homarus americanus: a demographic bottleneck? Mar Ecol Prog Ser 69:231-243

Manuscript first received: May 5, 1995

Revised version accepted: February 26, 1996 